\title{
Teacher's Perception: Designing Step-by-Step LOC-R (Literacy, Orientation, Collaboration, Reflection) in Sociocultural Literacy Teaching
}

\author{
Nuansa B. Segara ${ }^{1, *}$ Zulfahmi Alwi ${ }^{2,}$ Lilik Huriyah $^{3,}$ Ai R. Musyaropah ${ }^{4}$, \\ Saifuddin Saifuddin ${ }^{5}$, Shofar S. Bisri ${ }^{6}$ \\ ${ }^{l}$ Departement of Social Science Education, Universitas Negeri Surabaya, Surabaya, Indonesia \\ ${ }^{2}$ Departement of Islamic Law, Universitas Islam Negeri Alaudin, Makassar, Indonesia \\ ${ }^{3}$ Departement of Manag. \& Islamic Education, Universitas Islam Negeri Sunan Ampel, Surabaya, Indonesia \\ ${ }^{4}$ MIN 7 Ciamis, West Java District Ministry of Religious Office, Ciamis, Indonesia \\ ${ }^{5}$ MAN 2 Kudus, Cental Java District Ministry of Religious Office, Kudus, Indonesia \\ ${ }^{6}$ Tegal Ministry of Religious Office, Ministry of Religious, Tegal, Indonesia \\ *Corresponding author. Email: nuansasegara@unesa.ac.id
}

\begin{abstract}
Sociocultural literacy is required in Indonesia to sustain the nation's integrity. As a result, the Ministry of Religious included it in the AKMI component. It is essential in developing creative learning in the future post-AKMI learning environment in 2021. This article exposes the step-by-step LOC-R paradigm, which became an alternative to study sociocultural literacy following the adoption of AKMI. During the process of designing learning activities from this set of LOC-R stages, there is also a teacher's perspective to consider. Literacy, orientation, collaboration, and reflection are all highly important steps in building sociocultural literacy competences, since they steadily develop students' cognitive processes. The author of the module, which includes eight learning activities using LOC-R syntax, claims that development will be simple provided teachers understand the flow, principles, and basics of sociocultural literacy acquisition.
\end{abstract}

Keywords: AKMI, Social-cultural literacy, Collaboration, Orientation, Reflection.

\section{INTRODUCTION}

Sociocultural literacy is one of the components of the Ministry of Religious's Assessment Competence Madrasah Indonesia (AKMI). There are four additional components, which are as follows: 1) Literacy in Reading; 2) Literacy in Numeracy; 3) Literacy in Science; and 4) Character Survey. Sociocultural literacy has to be mapped due to Indonesia's very rich diversity background. Diversity in ethnic, religious, cultural, character, and so on has become Sunna that Indonesians cannot reject. This asset is also an impediment as the Indonesian community, which has been independent for 76 years, continues to lose sight of its national values. If the nation abandons the principle of "Bhinneka Tunggal $I k a$ ", the nation's uniting jargon, it will be exceedingly dangerous.
These are the reasons why sociocultural literacy must be assessed as a component in AKMI. According to the AKMI framework, sociocultural literacy is the ability to know, respond, reflect, evaluate, and create knowledge, attitude plans, and action plans related to national commitment, tolerance, nonviolence, accommodative and inclusive, designed based on the disciplines of history, sociology, anthropology, and relevant strategic issues, and associated with personal, societal, and religious contexts so that they can be used to improve knowledge and participation in peer learning [1].

The preceding knowledge reveals that the development of sociocultural literacy is integrally linked to the development of high-level thinking of Madrasah (Islamic Based School) learners. AKMI also includes four categories for sociocultural literacy: 1) national commitment; 2) tolerance; 3) nonviolence; and 4) accommodative and inclusive. It is also separated into 
three contexts: personal, societal, and religious. Sociocultural literacy is divided into three cognitive stages based on cognitive development [1]:

- Level 1 thinking is primarily designed to equip students with topic-specific information, knowledge, and understanding.;

- Level 2 thinking is structured so that students spend the majority of their time applying knowledge on the topic; and

- Level 3 thinking is designed so that students spend the majority of their time using knowledge to develop analytical, assessment, and synthesis abilities in order to create something new.

Following the implementation of AKMI, the Ministry of Religious Affairs has developed a follow-up program targeted at improving madrasah learning for all literacy, including sociocultural literacy. A follow-up team was formed to develop a novel learning series in the form of modules. The sociocultural literacy follow-up team also designed courses to help learners improve their sociocultural literacy competencies. The LOC-R model, a learning approach consisting of literacy, orientation, collaboration, and reflection, is one that is suggested in follow-up learning of sociocultural literacy. The aim of this article is to outline the stages involved in learning the LOC-R model. Furthermore, the purpose of this article is to reveal the perspectives of a team of module authors that designed eight learning activities employing the LOC-R model.

\section{METHODS}

This research approach is descriptive qualitative. This research was conducted through direct observation and interview with the author during the module writing process. The respondents in this research were five people. This source designed eight learning activities using the LOC-R model for three months. The observation was conducted via online as many as six meetings and two offline meetings. The instrument used was a human instrument, because the researcher himself directed the writing of the module of his learning activities. The data analysis used was descriptive, so that the data generated from the data searching process were then analyzed and explained descriptively

\section{RESULTS AND DISCUSSION}

\subsection{The Theoretical Foundation and Principles of Learning}

The goal of improving learning in AKMI follow-up modules is to develop learners' sociocultural literacy competencies. In AKMI, sociocultural literacy attempts to accept universal human values in sociocultural settings that can be adopted with religious moderation. There must be a theoretical framework that serves as the foundation for this learning improvement process in order for learners to apply the information and values anticipated in sociocultural literacy in personal, social, and religious contexts.

The LOC-R learning model is based on Vygotsky's Theory. Vygotsky cited by [2] states that cognitive growth occurs first on a social level, and can then occur in individuals. Understanding others and building knowledge on such a social level allow learners to connect themselves to circumstances. This theory is part of the paradigm of social constructivism. The construction of knowledge, attitudes, values, and behavior in this theory is developed through social processes [3,4]. Learning activities that focus on collaboratively and cooperatively improving the potential of learners will be able to assist maximum cognitive development. Teachers, peers (with better compatibility), and parents are suggested partners to assist students in improving their cognitive abilities.

There are learning principles based on the theory of social constructivism that are intended to maximize the process and outcome of learning, namely:

Sociocultural learning. According to Vygotsky, there should be a greater focus on the role of adults or peers who are more capable of learning. Vygotsky proposes utilized learning groups with various group members' abilities to aim for conceptual transformation. More social development studies in the early 21 st century focus on the antecedents (e.g., parental practices, social or cultural contexts) of a child's outcome s (e.g., social, psychological, and academic well-being [5]. However, currently social development theory is also practiced in learning activities. The teacher/mother must acquaint students in order for them to be adaptable in learning activities, whether they are done individually or in groups. There will be sociocultural interactions between members of various groups in terms of academic competence, sociocultural background, and emotional level at the stage of group activities. It is also extremely beneficial in developing sociocultural literacy abilities that lead to behavioral change [6].

Vygotsky defined Zone of proximal development (ZPD) as a zone in which learners have the ability to gain cognitive knowledge. ZPD achievement may be achieved by engaging learners with relevant and challenging knowledge, and by enabling their desire to study. Learners will have stronger cognitive development at that point with a little peer or adult assistance $[7,8]$.

Cognitive apprenticeship is the process in which a person who is learning step by step to acquire cognitive development, interact with adults or higher peers knows $[9,10]$. So, it will be more effective to assign tasks to learners with whom they can work as groups and individuals [8]. 
Scaffolding gives learners a large or small amount of assistance at the stage where the learners have difficulty in the learning process. It also helps to then reduce the assistance and to allow the students to take greater responsibility after they perform the task without anyone's help. There are several strategies in scaffolding, namely: 1) conceptual scaffolding; 2) procedural scaffolding; 3) strategic scaffolding; 4) metacognitive scaffolding [11].

\subsection{LOC-R: Step-by-Step}

LOC-R is a learning model that has been developed in 2018 [12]. There are slight modifications, initially, this is learning that focuses on map literacy, but it is considered to be used as a learning model that can develop literacy skills. To that end, LOC-R is a trial for use in a broader context. Here are the stages of LOC-R learning accompanied by descriptions of activities and examples of learning activities.

- Step 1: Literacy. The stage at which learners perform literacy activities independently to understand, respond, reflect, evaluate, create knowledge, plan attitudes and action plans of a stimulus. Teachers can provide questions for the development of students' sociocultural literacy skills. Conor stimulus literacy such as reading text (news, short stories, narration, informative reading), Infographics, Role Playing Scripts, Images, Videos, Animation, Cases, problems. At this stage also the teacher can give some critical questions, or learners are asked to write down what the question is.

- Step 2: Orientation. The stage where the teacher explains the purpose of learning in which learning activities are carried out to construct knowledge of facts, concepts, and values by considering the competence of sociocultural literacy. For example, learning activities are conducted are by using worksheets such as short staffing, matchmaking, identification of social or cultural values, conceptual understanding, and clarification of values.

- Step 3: Collaboration. Learning activities involve collaboration between learners and teachers and fellow students. This learning activity directs to increase cognitive levels with the help of partners, teachers, peers, and parents. This step provides learning activities with challenging tasks. It can also plan attitudes or actions following the competence of sociocultural literacy for higher-level works skills; teachers can give tasks like a mind map, short essay, script, story, or pictures and posters. Collaboration while completing tasks helps students improve their problem-solving skills, reflect on their learning and move on to the next step in their learning. In addition, classroom interaction helps teachers to obtain evidence of student learning and helps use to ensure student learning [13]. The fundamental idea is learners do not passively react in the middle of stimuli, but they will actively determine their own behavior through the creation of other stimuli [14].

- Step 4: Strengthening/repeating/concluding or synthesis related to learning activities or materials during learning activities. Learning activities were carried out such as: filling out a column, concluding and knowing the benefits of the material studied and mentioning the difficulties faced.

Each learning step in the LOC-R model should be tiered according to cognitive level. The literacy stage is carried out learning activities that are relatively easy and at a low cognitive level. Furthermore, in the orientation stage, teachers can increase their cognitive level. It culminates in the collaboration stage, which is expected to develop cognitive processes significantly, so learners must be faced with challenging tasks.

\subsection{Discussion}

Five selected teachers were allowed to develop LOC$\mathrm{R}$ learning activities by designing modules for teachers that contained examples of worksheets as learners' learning guidance. In the early stages, teachers are given directions to ensure the existence of perception equality. The companion's direction concentrated on various aspects, including: 1) the theoretical foundation; 2) the principles of learning; 3) different forms of learning activities; and 4) the cognitive level. These five teachers work on modules that have five levels of proficiency based on diagnostic assessment results. The five levels of proficiency are as follows: 1) the level that requires intervention; 2) the basic level; 3) the level of skill; 4) the skilled level; and 5) the level that requires intervention.

Each level's character is a variation in competence that represents the cognitive development of these levels. This is repeatedly highlighted throughout each session of discussion and assessment of the preliminary draft of the LOC-R learning plan. The most challenging part of planning for instructors at the beginning is choosing the stimulus at the literacy stage. Teachers as designers are not yet accustomed to designing or choosing the stimulus used as a starting point for learning activities.

Author 1 appears to be having a difficult time determining the stimulus since it is focusing on searching from internet sources. When determining the domain of national commitment, it is important to consider the stimulus so that it falls inside the learning objectives. According to Author 1, "finding the proper stimulus is rather challenging when searching from internet sources, because the subject raised is not necessarily appropriate, as it must be adapted or modified." Author 3 is already experiencing challenges similar to author 1 , therefore he immediately took the initiative to adapt a short narrative to serve as a stimulus in the domain of national commitment. 
According to Author 2, "to obtain the appropriate stimulus, there must be a sufficiently time-consuming reflection and search for reference sources." So, at the beginning of the draft writing process, every author appears to work rather slowly since it is still unclear what learning activities are fitted to the features of LOC-R in sociocultural literacy acquisition. Author 5 requires minor notes to select a narrative book that meets the learning objectives of sociocultural literacy.

Furthermore, in developing the orientation stage learning activity, the author should seek for references from other nations to ensure that it seems contemporary and innovative. The author selected learning exercises such as matching, cases, fryer diagrams, and mind mapping. This learning exercise is adapted to each cognitive level's degree of competency, as well as learning concepts based on Vygotsky's theory [15]. The focus of sociocultural literacy learning is, indeed, on the development of students' knowledge of universal values that arise in the Indonesian setting.

At the collaboration stage, teams must design a challenging learning activity that is more difficult. It is done in a way to encourage students interacting socially with other students and teachers in order to achieve the tasks. "The determination of activities at the collaboration stage is particularly essential," author 4 stated, "since it is at this time that students accomplish their best cognitive development." All learning activities in the collaboration stage must be immediately matched with student characteristics and school requirements. According to author 2, "group discussion activities have become one of the simple options to developing learning activities."

The author has a lot of freedom during the reflection stage, yet some authors are still preoccupied on the question. Should the activity be centered on the points that have been pursued? What's the difficulty? And what advantages do you gain from the learning process? The author is a little preoccupied on the notion that contemplation is an ending activity. Author 5 seems boring when reflecting on learning activities; thus, it should be directed by the director so that there are changes in the draft plan.

In general, authors may easily design LOC-R for sociocultural literacy learning. However, several essential factors are taken into account while designing learning activities. The level of proficiency is essential since it influences the level of cognitive and competency that students must acquire. Authors 1 and 2 struggled owing to poor cognitive levels at basic proficiency levels and required interventions that were compatible with the simplicity of their learning activities. The challenge is ensuring that learning activities are planned in accordance with fundamental proficiency level achievements and that intervention is required. According to authors 3 and 5, "this LOC-R sink would be quite strong if it was practiced well in the classroom." For that, it needs a complete understanding of the users of this model.

It takes numerous attempts to make a sequence of LOC-R learning activities intact in order to swiftly create new learning activities. Authors who are familiar with and understand the flow of LOC-R synthesizers will find it easy to design the complete learning stage. Starting with a stimulus in the reading stage and it progresses to a sequence of learning tasks in the orientation and collaboration stages. Then, during the reflection stage, innovative activities are planned. To build modules with examples of sociocultural literacy learning activities, active dialogues and reviews are required. Review is often given particularly at each level of learning activities. The entire module is finally completed and is sufficiently satisfactory to external reviewers.

\section{CONCLUSION}

LOC-R is a type of alternative learning model that is intended to develop sociocultural literacy skills. The literacy step is the first in this learning activity, and it provides students with a trigger to begin learning activities. The orientation phase is the second in a series of learning activities in which students are guided by the teacher to develop the idea of values in the domain of sociocultural literacy. The third stage is collaboration, in which students are supposed to attain the maximum cognitive development through social contact with teachers. Developers (madrasah teachers) would have challenges in developing learning activities at first, However, after students understand the flow and key elements that must be addressed in the design, it will rapidly organize a series of learning activities on LOC-R. As a result, understanding the concepts, objectives, domains, and cognitive levels of sociocultural literacy is important in compiling improvements within sociocultural literacy learning. In order to design sociocultural literacy learning activities with LOC-R syntax, it is also necessary to understand the theoretical foundations and learning principles employed in LOC-R.

\section{AUTHORS' CONTRIBUTIONS}

All authors have different roles in the accomplishment of the study. For this manuscript, they contributed equally to the process of drafting, revision, and approval of the final revision.

\section{REFERENCES}

[1] Z. Alwi, Literasi Sosial Budaya, 2021.

[2] R. J. Amineh, H. D. Asl, Review of Constructivism and Social Constructivism, Journal of Social Sciences, Literature, and Languages 1(1) (2015) 916. 
[3] D. Bakhurst, Understanding Vygotsky, Learning, Culture and Social Interaction 5 (2015) 1-4. DOI: https://doi.org/10.1016/j.lcsi.2014.06.001

[4] A. Kozulin, B. Gindis, S. V. Ageyev, M. S. Miller, Vygotsky's Educational Theory in Cultural Context. New York: Cambridge University Press, 2003.

[5] K. R. Olson, C. S. Dweck, A Blueprint for Social Cognitive Development, Perspectives on Psychological Science 3(3) (2016) 193-202.

[6] H. Daniels, An Introduction to Vygotsky. London and New York: Routledge, 2003.

[7] T. Fani, F. Ghaemi, Implications of Vygotsky ' $s$ Zone of Proximal Development ( ZPD ) in Teacher Education: ZPTD and Self-scaffolding, Procedia Social Behavioural Science, 29(Iceepsy) (2011) 1549-1554.

DOI: https://doi.org/10.1016/j.sbspro.2011.11.396

[8] M. Bekiryaz, Teaching Mixed-Level Classes with A Vygotskian Perspective, Procedia - Social Behavioural Science 186 (2015) 913-917. DOI: https://doi.org/10.1016/j.sbspro.2015.04.163

[9] D. A. Kolb, Experiential Learning: Experience as the Source of Learning and Development, Pearson Education, Inc, 2015.

[10] J. V. Wertsch, Vygotsky and recent developments, International Encyclopaedia of Education (2010) 231-236. DOI: https://doi.org/10.1016/B978-0-08044894-7.00490-5

[11] N. Phumeechanya, P. Wannapiroon, Design of problem-based with scaffolding learning activities in ubiquitous learning environment to develop problem-solving skills, Procedia - Social Behavioural Science 116 (2014) 4803-4808. DOI: https://doi.org/10.1016/j.sbspro.2014.01.1028

[12] N. B. Segara, E. Maryani, N. Supriatna, M. Ruhimat, Introducing Map Literacy Model of Learning, IOP Conference Series: Earth and Environmental Science 145(1) (2018). DOI: https://doi.org/10.1088/1755-1315/145/1/012046

[13] S. Abbasnasab, M. Rashid, M. Saad, Knowledge with Professional Practice A Sociocultural Perspective on Assessment for Learning: The Case of a Malaysian Primary School ESL Context, Procedia - Social Behavioural Science 66 (2012) 343-353.

DOI: https://doi.org/10.1016/j.sbspro.2012.11.277

[14] H. Daniels, M. Cole, J. Wertsch, The Cambridge Companion to Vygotsky, New York: Cambridge University Press, 2007.
[15] K. M. A. Churcher, E. Downs, D. Tewksbury, Friending' Vygotsky: A Social Constructivist $\mathrm{P}$ edagogy of Knowledge Building Through Classroom Social Media Use, Journal of Effective Teaching 14(1) (2014) 33-50. 